\title{
As plantas medicinais e a etnobotânica em Várzea Grande, MT, Brasil
}

\author{
Plants in medical and ethnobotany in Varzea Grande, MT, Brazil \\ Plantes médicinales et ethnobotanique à Varzea Grande, MT, Brésil
}

Plantas medicinales y el etnobotánica en Varzea Grande, MT, Brasil

\author{
Margô De David* \\ (margodedavid@bol.com.br) \\ Maria Corette Pasa* \\ (pasamc@brturbo.com.br)
}

Recebido em 11/09/2013; revisado e aprovado em 10/05/2014; aceito em 23/07/2014

DOI: http://dx.doi.org/10.1590/1518-70122015108

\begin{abstract}
Resumo: O estudo realizado em Várzea Grande, MT objetivou resgatar o conhecimento sobre as plantas usadas como remédio, o quanto a utilizam e a finalidade do uso. Aplicou-se o pré-teste, entrevistas semiestruturadas e observação direta, no período de março a julho/2013. Foram citadas 86 espécies em 45 famílias, sendo Fabaceae e Mimosaceae as mais expressivas. A folha é a mais utilizada e o modo de preparo é o chá, de uso medicinal. O processo de conservação e o manejo são evidentes no cotidiano local.

Palavras-chave: Etnobotânica. Manejo. Conservação.

Abstract: The study aimed at rescuing the Várzea Grande, MT knowledge of plants used as medicine, how to use and purpose of use. Used the pre-test, semi-structured interviews and direct observation in the period from march to julho/2013. Were cited 86 species in 45 families, Fabaceae and Mimosaceae being the most significant. The leaf is the most used and the method of preparation is tea, for medical use. The process of conservation and management are evident in everyday local.

Key words: Ethnobotany. Management. Conservation.

Résumé: L'étude vise à sauver la Várzea Grande, MT connaissance des plantes utilisées comme médicaments, l'utilisation et la finalité de l'utilisation. Nous avons utilisé les pré-tests, entretiens semi-directifs et observation directe dans la période de mars à julho/2013. On a cité 86 espèces dans 45 familles, Fabaceae et Mimosacées étant la plus importante. La feuille est le plus utilisé et le mode de préparation du thé, à des fins médicales. Le processus de conservation et de gestion sont évidents dans la tache quotidienne.

Most-clés: Ethnobotanique. Gestion. Conservation.

Resumen: El estudio llevado a cabo en Várzea Grande, MT objetivo de rescatar el conocimiento sobre las plantas utilizadas como medicinale, el uso y la finalidad de su uso. Se utilizaron las entrevistas semiestructuradas y observación directa en el período de marzo a julho/2013. Se mencionaron 86 especies en 45 familias, Fabaceae y Mimosaceae siendo los más significativos. La hoja es el más utilizado y el método de preparación es el té, para los propósitos médicos. El proceso de conservación y gestión son evidentes en lugar todos los días.

Palabras clave: Etnobotánica. Management. Conservación.
\end{abstract}

\section{Introdução}

Com base na evolução histórica do uso de plantas medicinais, a Organização Mundial deSaúde(OMS), em 1978, passou a reconhecer a fitoterapia como terapia alternativa de enfermidades humanas (SANTOS et al., 2009). Na década de 1990, estimou-se que a maioria da população mundial dependia essencialmente de plantas medicinais para os cuidados básicos de saúde (AKERELE, 1993). A utilização de plantas medicinais para tratamento, cura e prevenção de doenças é uma das mais antigas formas de prática medicinal da humanidade.

A etnobotânica desponta como o campo interdisciplinar que compreende o estudo e a interpretação do conhecimento, da significa- ção cultural, do manejo e dos usos tradicionais dos elementos da flora (CABALLERO, 1979). Assim, os estudos etnobotânicos vão além do que pode pretender a investigação botânica, uma vez que suas metas se concentram em torno de um ponto fundamental, que é a significação ou o valor cultural das plantas em uma determinada comunidade rural (BARRERA, 1979). Numa dada população, nem todos os membros conhecem todas as plantas; no entanto as mulheres, quase sempre envolvidas diretamente no tratamento de seus filhos e maridos, são, em geral, as principais depositárias do saber popular quanto ao uso das plantas. Entre as plantas utilizadas em várias sociedades, existem aquelas que podem, frequentemente, ser usadas para mais de uma

* Universidade Federal de Mato Grosso - UFMT, Cuiabá, MT, Brasil. 
doença. Várias espécies também podem ser usadas tanto separadamente como em combinação para tratar uma doença específica. A opção pela planta a ser utilizada é feita pela combinação da experiência vivida no dia a dia e da magia que as envolve.

No Brasil, o uso de plantas medicinais pela população, com a finalidade de tratar enfermidades, foi sempre expressivo, principalmente devido à extensa e diversificada flora. Ainda hoje, nas regiões mais pobres do país e até mesmo nas grandes cidades, plantas medicinais são comercializadas em feiras livres e mercados populares, sendo também encontradas em quintais residenciais (ALMEIDA, 1993; AGRA et al., 2008; MARLIÉRE et al., 2008; VEIGA JUNIOR, 2008; LEITÃO et al., 2009; SANTOS et al., 2009).

Em se tratando de saber local, Amorozo e Gély (1988) ressaltam que, em muitos casos, ele representa o único recurso terapêutico disponível que a população rural tem ao seu alcance. A origem desse saber popular se encontra na observação constante e sistemática dos fenômenos e das características da natureza e na consequente experimentação empírica desses recursos, o que justifica a importância e a posição que as plantas medicinais assumem nos resultados das investigações etnobotânicas de uma região ou mesmo de uma sociedade (ALBUQUERQUE; ANDRADE, 2002). A descoberta de drogas, como os alcalóides do grupo tropano, extraídos da beladona (Atropa belladona L.), da família Solanaceae, usados como antiespasmódicos na medicina moderna, teve como orientação o uso empírico para tratar os males de uma população (ELIZABETSKY,1987). Para Amorozo e Gély (1988), as razões para preferir o uso de uma planta como medicinal por caboclos de Barcarena, no baixo Amazonas, Pará, encontram-se fundamentadas no sistema de pensamento e crenças, com concepções de causa e efeito próprios. As observações feitas pelos caboclos demonstram uma grande convivência com o mundo vegetal ligada à experimentação e às investigações constantes das propriedades terapêuticas das plantas.

Em se tratando do conhecimento tradicional de populações humanas de diferentes regiões do cerrado de Mato Grosso, destacamse as contribuições de vários autores voltadas para o estudo das plantas medicinais, como
Farnsworth (1981), Guarim Neto (1984), De La Cruz e Guarim Neto (1996), Pasa et al. (2005), Borba e Macedo (2006), Pasa (2007, 2011), entre outros, que discutem aspectos relacionados à biodiversidade, ao ambiente e à relação do ser humano e as plantas, ampliando o saber local dos recursos do bioma e dos povos que o habitam.

Por meio da investigação científica de agentes biologicamente ativos, usados na medicina popular, a etnofarmacologia vem documentando e avaliando os agentes medicinais adotados em práticas tradicionais, bem como o desenvolvimento de medicamentos sem o uso da metodologia industrial. Para isso, a informação coletada junto à população a respeito do uso de plantas é de fundamental importância, ressaltando que as plantas medicinais estão sendo revalorizadas porque, entre outras razões, é a forma mais acessível para a população local curar suas enfermidades (PASA, 2011). Assim, o presente estudo objetivou resgatar o conhecimento da população local sobre o uso de plantas como remédio e, por meio do tratamento quantitativo, determinar a importância das espécies mencionadas pelas pessoas da comunidade.

\section{Material e métodos}

O município de Várzea Grande está localizado no Estado de Mato Grosso, designado pelo Projeto Radambrasil (BRASIL, 1982) como uma região da Depressão Cuiabana e delimitado pelas coordenadas $15^{\circ} 39^{\prime} 01,91^{\prime \prime} \mathrm{S}$ $56^{\circ} 08^{\prime} 41,69^{\prime \prime} \mathrm{W}$.

O clima da região é tropical semiúmido (Aw na classificação de Köppen), com precipitação pluviométrica anual de $1.350 \mathrm{~mm}$ (INMET, 1996) e apresenta duas estações bem definidas: a seca, que vai de abril a outubro, e a chuvosa, que vai de novembro a março. A temperatura média anual é de $26^{\circ} \mathrm{C}$, com mínimas de $15^{\circ} \mathrm{C}$ e máximas de $32^{\circ} \mathrm{C}$, e a umidade relativa do ar varia muito, com a média anual em torno de 74\% (FUNASA, 2007). O solo é classificado como argissolo vermelho amarelo distrófico, de textura arenosa média (MACHADO et al., s.d.). A vegetação é composta por savana arbórea aberta (cerrado), capoeira e mata ciliar (OLIVEIRA, 2008).

O período de execução da pesquisa ocorreu entre março a julho de 2013. Ini- 
cialmente, procedeu-se a um levantamento e mapeamento da região, e à aplicação do pré-teste para selecionar e testar as técnicas a serem utilizadas junto à população local. Foi escolhido ao acaso quatro bairros e oito ruas em cada um, totalizando 68 informantes.

A coleta de informações consistiu na aplicação de entrevistas semiestruturadas (MINAYO, 1992), abordando aspectos socioeconômicos e culturais, e na observação direta para coletar dados quanto ao uso das plantas e às formas de uso nos diferentes tratamentos das afecções orgânicas que acometem a população da região. As espécies coletadas foram identificadas por especialistas do Herbário Central da Universidade Federal de Mato Grosso (UFMT), onde se encontram depositadas.

$\mathrm{O}$ valor de uso das plantas quanto à finalidade foi determinado por meio do nível de fidelidade (NF) de cada uma, segundo Phillips (1996), Friedman (1986), Pasa (2011), Pasa e Oliveira (2013). O cálculo consiste na razão entre o número de informantes que sugeriram o uso de uma espécie para uma finalidade maior (Fid) pelo número total de informantes que mencionaram a planta para algum uso (Fsp), multiplicado por 100. Assim, $\mathrm{NF}=($ Fid/Fsp $) \times 100$. O consenso informante permite avaliar a importância relativa de cada planta, calculada diretamente sobre o grau de consenso das respostas dos informantes (ADU-TUTU et al., 1979; Friedman, 1986), permitindo definir a Importância de Concordância de Usos principais (ICUsp) e o Número de Usos mencionados pelos informantes para cada espécie (NU).

\section{Resultados e discussão}

Os resultados mostram que a maior parte dos entrevistados é procedente de Mato Grosso (69\%) e o restante $(31 \%)$ vem de outros estados, como Mato Grosso do Sul, Paraná, Rio Grande do Sul, Goiás, São Paulo e Minas Gerais. O número de pessoas que compõe a família, em média, é de quatro a cinco membros. Usualmente, o casal tem dois ou três filhos. A amostra foi de 68 pessoas, sendo $52 \%$ do sexo feminino e $48 \%$ do sexo masculino. Idosos acima de 60 anos de idade representaram 14\%. Entre os entrevistados, $45 \%$ não possuem escolaridade e, quanto aos alfabetizados, $50 \%$ possuem o ensino fundamental incompleto e $5 \%$ concluíram a 8 a série do ensino fundamental. Não houve registro de andamento ou de conclusão de ensino médio e superior.

Dados obtidos das entrevistas apontam que as mulheres, na sua maioria, desempenham atividades domésticas, e os homens, atividades em lojas, supermercados, oficinas, restaurantes etc. ou são aposentados. Quando questionadas sobre a renda familiar e/ ou individual, as pessoas se manifestaram, de um modo geral, com certa abstração, não sendo, portanto, esse item considerado nas entrevistas. Isso não invalidou o restante das informações socioeconômicas levantadas, o que permitiu enquadrar essa população numa classe social de renda salarial baixa.

Os sistemas de quintais agroflorestais são conhecidos também como hortos caseiros onde ocorre o uso da terra na qual várias espécies de árvores são cultivadas junto com culturas perenes e anuais e, ocasionalmente, criação de pequenos animais ao redor da casa.

Ao produzir alimentos para a subsistência da família, o quintal exerce considerável papel econômico na vida dessas pessoas. Em geral, os quintais locais constituem-se de tamanho suficiente para atender a demanda familiar e de grande número de espécies perenes e de uma variedade de espécies que permite a produção ao longo de ano. Além disso, possui uma cobertura vegetativa diversificada sobre o solo. A produção vegetal nos quintais pode ser dividida em (1) frutífera como laranja, limão, manga, café, acerola, caju, goiaba, mamão, maracujá, abacate, algodãozinho, gergelim, mamona etc.; (2) hortaliça como alface, rúcula, almeirão, couve, cenoura, abóbora, tomate, beterraba, pimentão etc.; (3) remédio erva de bicho, velame, carobinha, jaborandi, genipapo, urucum, jurubeba, tamarindo, fedegoso, capim cidreira, quebra-pedra, algodãozinho, poejo, guaco, boldo etc.

Outra função importante desempenhada pelas espécies perenes é o sombreamento que promovem no espaço denominado quintal. Além do sombreamento, proporcionam uma melhor infiltração da água na terra que promove a formação de matéria orgânica que mantém a variedade das espécies ali existentes. Aliado à baixa densidade por espécie e à 
alta diversidade de culturas nos quintais, os diferentes ciclos biológicos das espécies oferecem a possibilidade de um baixo índice de riscos quanto a pragas e doenças que possam representar ameaça às espécies.

O processo de domesticação proporciona a diversidade genética intraespecífica, com isso, nota-se que a tendência é de aumentar o número de espécies usadas, manejadas, cultivadas e domesticadas. Assim, a alta diversidade das plantas nos quintais representa um verdadeiro banco de germoplasma como fonte de sustentabilidade local.

O tratamento dispensado ao quintal é diferenciado em função da sua multiplicidade de uso pelos membros da família, parentes e amigos. Além de representar o espaço das plantas úteis, o quintal serve, também, para representar o espaço de trabalho, de festas, de convívio familiar, de encontros de amigos e vizinhos, sendo, portanto, um espaço que representa a cultura popular mato-grossense.

É através da produção hortifrutífera nos quintais que a população mantém (1) a baixa dependência de produtos adquiridos externamente, (2) apresenta impactos negativos mínimos sobre o ambiente, (3) conserva os recursos vegetais e diversidade cultural fundamentada sobre o saber e a cultura dos moradores locais, (4) utiliza os insumos naturais promovendo a reciclagem de elementos naturais, favorecendo, dessa forma, um ambiente sustentável, atendendo as necessidades para a subsistência; (5) fortalece o espírito de cooperação entre as pessoas da comunidade local.

Quanto à composição florística presente nos quintais agroflorestais, Nair (1993) destaca que, apesar da seleção das espécies serem determinadas por fatores socioeconômicos, culturais e ambientais, ocorre uma similaridade entre os quintais distribuídos na região tropical, especialmente com relação aos componentes herbáceos. E, que essa similaridade deve-se ao fato de a produção de remédios e alimentos serem a função predominante da maioria das espécies herbáceas encontradas nos quintais. Cita também que a arquitetura de um subdossel seleciona as espécies tolerantes à sombra, ou seja, espécies que apresentam características ecológicas de adaptação a esses ambientes. Portanto a composição das espécies vegetais presentes nos quintais influenciará o padrão de produção e o ritmo de manutenção desse ecossistema.

A estrutura espacial dos componentes vegetais presentes nos quintais de Várzea Grande apresenta, em média, três estratos: herbáceo, subdossel e o dossel. Verticalmente os três estratos podem, a exemplo, serem representados da seguinte forma: o estrato mais alto representado por árvores altas como manga, copaíba e mamão; o estrato intermediário representado por árvores de altura média e arbustos incluindo a laranja, limão, abacate; e o estrato inferior ocupado por culturas agrícolas como pepino, tomate, ervas medicinais, condimentos e plantas ornamentais.

Guarim Neto (1984) publicou preliminar acerca de plantas medicinais utilizadas na medicina popular cuiabana com maiores enfoques para aquelas cultivadas nos quintais das antigas moradias. E, considerando as populações humanas, a flora medicinal e o ambiente do cerrado, o autor evidencia as potencialidades dos recursos vegetais no Mato Grosso envolvendo a biodiversidade, onde os estudos realizados em várias regiões mostram que as etnocategorias (categorias de uso popular, estabelecidas pelos seres humanos), uma vez transpostas para o meio técnico-científico, são traduzidas e determinam fatores significativos em pesquisas nas mais diferentes áreas do conhecimento humano destacando-se o estudo integrado de plantas com finalidades medicinais.

Em se tratando da medicina popular mato-grossense, Borba e Macedo (2006) destacam o uso das plantas medicinais encontradas nos quintais das residências, registrando a utilização de 87 espécies, dentro de 48 famílias, com um total de 47 indicações terapêuticas para afecções bucais que acometem os habitantes do bairro Santa Cruz, em Chapada dos Guimarães. A espécie com maior número de citações foi a camomila (Matricaria chamomilla L.), seguida da laranjeira (Citrus aurantium L.), do poejo (Mentha pulegium L.) e da marcela (Achyrocline satureioides (Lam.) DC). arnicado-campo (Camarea ericoides St. Hil.), da camomila, da mangava-brava (Lafoensia pacari A. St.-Hil.) e da tanchagem (Plantago major L.). Os autores constataram que diversas espécies vegetais são usadas pela comunidade com finalidade terapêutica em relação à manutenção e recuperação da saúde bucal: plantas 
nativas, encontradas no cerrado, e plantas exóticas, cultivadas em quintais.

Nos bairros de Várzea Grande, as espécies de plantas medicinais nativas continuam sendo bastante usadas, apesar de o número de espécies exóticas ser maior em relação às plantas citadas. A maioria das espécies apresenta hábito herbáceo (32\%), seguido de arbustivo (23\%) e arbóreo (16\%). A parte da planta mais utilizada é a folha $(48,3 \%)$, seguida do caule $(14,3 \%)$ e da raiz $(12 \%)$. A preferência da folha no preparo dos remédios caseiros é um costume que mostra o cuidado a preservação de recursos naturais da região. As plantas são utilizadas in natura ou após serem colocadas para secar a sombra por período de cinco a sete dias, permitindo o armazenamento por alguns meses, utilizando métodos empíricos aproximados das técnicas encontradas em comunidades mato-grossenses por Pasa (2007).

Observou-se na comunidade que existem semelhanças e diferenças na maneira de se preparar a planta para ser utilizada. Alguns preferem o chá de uma planta por decocção, enquanto outros acreditam que a mesma planta, por infusão, torna-se mais saborosa e eficaz. Uns usam mais as folhas do vegetal, enquanto outros acreditam que o efeito só é garantido utilizando a planta toda. Outras partes, como fruto, flor, semente e produtos extrativos (óleo e seiva, por exemplo) representam $25,4 \%$. A forma de preparo mais expressiva é o chá (68\%), por meio da utilização das folhas. Xaropes, garrafadas, infusões, macerados, emplastros, compressas e banhos de assento representaram $32 \%$.

Vendruscolo e Mentz (2006), ao abordarem o uso das plantas medicinais em um bairro de Porto Alegre, no RS, ressaltam a importância do valor de uso, da forma de coleta e do armazenamento das espécies Achyrocline satureioides (marcela) e Cuphea carthagenensis (sete-sangrias), entre outras com maior índice de importância para a comunidade, que são cultivadas nos pátios e/ou jardins e ainda adquiridas com vizinhos e amigos. Os autores também detectaram que a marcela é coletada nos campos ou em beiras de estrada, tradicionalmente na véspera da Semana Santa (uma semana antes da Páscoa), e que suas flores são postas para secar, sendo posteriormente guardadas para utilização. Também destacam Aloe arborescens, Achyrocline satureioides, Citrus limon, Citrus aurantium, Cunila microcephala, Eugenia uniflora, Foeniculum vulgare e Plectranthus barbatus, citadas por informantes pertencentes a todas as oito regiões em que o bairro é dividido pelo posto de saúde, possuindo, cada uma delas, mais de 30 citações de usos, demonstrando que o conhecimento sobre a utilização das espécies é igualmente distribuído no bairro.

Todas as plantas de uso medicinal mencionadas pelos informantes de Várzea Grande apresentaram o nome popular, a parte usada, o preparo e a indicação terapêutica, conforme Tabela 1. 
Tabela 1 - Plantas usadas como remédio nos quintais de Várzea Grande, MT. 2013.

\begin{tabular}{|c|c|c|c|c|}
\hline Nome Científico & Nome Popular & $\begin{array}{l}\text { Parte } \\
\text { Usada }\end{array}$ & Preparo & $\begin{array}{c}\text { Indicação } \\
\text { Terapêutica }\end{array}$ \\
\hline Mentha arvensis L. & Vick & Folha & Inalação & $\begin{array}{l}\text { Descongestionante } \\
\text { nasal }\end{array}$ \\
\hline Genipa americana L. & Genipapo & Fruto & In natura & Diabetes \\
\hline Hiptis suavialins L. & Tapera & Folha & Chá & Câncer \\
\hline Mimosa sp. & Dorme-dorme & Folha & In natura & Calmante \\
\hline Ruta graveolens L. & Arruda & Folha & Chá & Piolho \\
\hline Holcus mollis L. & Erva-molar & Folha & Chá & Rim \\
\hline Cissus sicyoides L. & Insulina & Folha & Chá & Diabetes \\
\hline Malpighia glabra L. & Acerola & Fruto & In natura & Vitamina \\
\hline Ocimum canum Sims. & Alfavaca & Folha & Chá & Colesterol \\
\hline Mangifera indica L. & Manga & Polpa & Suco & Vitamina e sinusite \\
\hline Lafoensia pacari A.St. -Hil. & Mangava- & Casca Folha & Infusão & Úlcera \\
\hline Uncaria tomentosa (Willd.) DC. & $\begin{array}{l}\text { brava } \\
\text { Unha-de-gato }\end{array}$ & Folha & Chá & Inflamação \\
\hline Cucurbita pepo L. & Abóbora & Semente & Chá & Vermífugo \\
\hline Gossypium herbaceum L & Algodão & Flor & Chá & $\begin{array}{l}\text { Inflamação do útero e } \\
\text { ovários }\end{array}$ \\
\hline Artemisia absinthium L. & Atemije & Folha & Chá & Febre, dor de cabeça \\
\hline Ruta graveolens L. & Arruda & Folha & Chá & Abortivo \\
\hline Vernonia ferruginea Less & Assa peixe & Folha & Infusão & $\begin{array}{l}\text { Diurético, dor na } \\
\text { bexiga }\end{array}$ \\
\hline Alloe vera $\mathrm{L}$. & Babosa & Sumo & Infusão & Úlcera, gastrite \\
\hline Coleus barbatus Benth & Boldo & Folha & Chá & Indigestão, tontura \\
\hline Vernonia polianthes L. & Caferana & Folha & Chá & Lavar feridas \\
\hline Matricaria recutita $\mathrm{L}$. & Camomila & Ramo foliar & Chá & Constipação intestinal \\
\hline Cymbopogum citratus L. & $\begin{array}{l}\text { Capim- } \\
\text { cidreira }\end{array}$ & Folha & Chá & Calmante \\
\hline Jacarandá semiserrata C. & Carobinha & Folha & Chá & Úlcera, gastrite \\
\hline Baccharis trimera Less. & Carqueja & Folha & Chá & Indigestão, tontura \\
\hline Alpinia speciosa Schum. & Colônia & Flor & $\begin{array}{l}\text { Banho-de- } \\
\text { assento }\end{array}$ & $\begin{array}{l}\text { Cólicas de baixo } \\
\text { ventre, pressão alta }\end{array}$ \\
\hline Symphytum officinale L. & Confrei & Folha & Chá & Úlcera, gastrite \\
\hline Lippia alba (Mill.) Blume & Erva cidreira & Folha & Chá & Gripe, calmante \\
\hline Polygonum acre H.B.K & Erva-de-bicho & Folha & Compressa & Hemorroida, varizes \\
\hline Eucalyptus sp & Eucalipto & Folha & Chá & Tosse, gripe \\
\hline Cássia occidentale L. & Fedegoso & Raiz & Macerada & $\begin{array}{l}\text { Tônico muscular e } \\
\text { fadiga }\end{array}$ \\
\hline Zingiber oficinalis Rosc. & Gengibre & Bulbo & Chá & $\begin{array}{l}\text { Gripe, dor de } \\
\text { garganta }\end{array}$ \\
\hline Petiveria alliacea L. & Guiné & Folha & Chá & Febre, gripe \\
\hline Passiflora edulis Sims. & Maracujá & Folha & Chá & Calmante \\
\hline Symphytum officinale L. & Confrei & Folha & Chá & Úlcera, gastrite \\
\hline Cássia occidentale L. & Fedegoso & Raiz & Macerada & $\begin{array}{l}\text { Tônico muscular, } \\
\text { fadiga }\end{array}$ \\
\hline Petiveria alliacea L. & Guiné & Folha & Chá & Febre, gripe \\
\hline Chenopodium ambrusioides L. & Mastruz & Folha & Chá & Vermífugo \\
\hline Sambucus nigra $\mathrm{L}$ & Sabugueiro & Folha & Chá & Tosse \\
\hline Scoparia dulcis & Vassourinha & Folha & Emplastro & Quebradura \\
\hline Stachytarpheta augustifolia & Gervão & Folha & Chá & Digestivo \\
\hline Lopez-Palacios & Jurubeba & Folha & Chá & Problemas do fígado \\
\hline Solanum aff.lycocarpum & Hortelã & Folha & Chá & Vermífugo \\
\hline Mentha piperita $\mathrm{L}$. & Barbatimão & Folha & Chá & Câncer \\
\hline Stryphnodendron adstringens (Mart.) & Anador & Folha & Chá & Diabetes \\
\hline Coville & Terramicina & Folha & Chá & Analgésico \\
\hline Justicia pectoralis Jacq. & Quebra-pedra & Folha & Chá & Antibiótico \\
\hline Alternanthera brasiliana (L.) Kuntze & Noni & Folha & Chá & Urinário \\
\hline Phyllanthus niruri L. & Manjericão & Folha & Tempero & Câncer \\
\hline Morinda citrifolia L. & Malva & Raiz & Chá & Imunidade \\
\hline
\end{tabular}




\begin{tabular}{|c|c|c|c|c|}
\hline Nome Científico & Nome Popular & $\begin{array}{c}\text { Parte } \\
\text { Usada }\end{array}$ & Preparo & $\begin{array}{l}\text { Indicação } \\
\text { Terapêutica }\end{array}$ \\
\hline Ocimum basilicum L. & Limão & Sumo & Suco & Dor de dente \\
\hline Malva sylvestris L. & Laranja & Casca & Infusão & Colesterol \\
\hline Citrus limonum Osbeck. & Jucá & Folha & Chá & Garganta \\
\hline Citrus aurantium L. & Hortelã & Folha & Chá & Circulação \\
\hline Caesalpinia ferrea Mart. & Guiné & Folha & Chá & Vermífugo \\
\hline Mentha piperita L & Hortelã & Folha & Chá & Calmante \\
\hline Petiveria alliacea L. & Gengibre & Raiz & Chá & Calmante \\
\hline Matricaria chamomilla L. & Camomila & Folha & Chá & Digestivo \\
\hline Zingiber officinalis L. & Gengibre & Raiz & Chá & Inflamações \\
\hline Phyllanthus orbiculatus M. Arg. & $\begin{array}{l}\text { Quebra- } \\
\text { pedra }\end{array}$ & Folha & Chá & Inflamação dos rins \\
\hline Punica granatum L. & Romã & Casca & Chá & $\begin{array}{l}\text { Inflamação da } \\
\text { garganta }\end{array}$ \\
\hline Sambucus nigra L. & Sabugueiro & Folha & Chá & Febre, tosse \\
\hline Smilax sp & Salsaparrilha & Raiz & Chá & Reumatismo \\
\hline Colocasia sp & Taioba & Folha & Chá & Depurativo do sangue \\
\hline Lycopersicum esculentum Mill & Tomate & Folha & Chá & Diurético \\
\hline Bactris glaucescens Drude & Tucum & Fruto & Chá & Vermífugo \\
\hline Scoparia dulcis L. & Vassourinha & Folha & Emplastro & $\begin{array}{l}\text { Machucaduras, } \\
\text { quebraduras }\end{array}$ \\
\hline
\end{tabular}

Os resultados conferem a importância da diversidade de espécies encontrada nos quintais como forma de atender as necessidades de autoconsumo familiar e, dessa forma, expressando a força da influência cultural quanto ao uso e à manutenção das diversas plantas que fazem parte da estrutura paisagística nos quintais locais. A categoria de uso medicinal apresentou expressividade para o total das espécies existentes nos quintais das moradias, o qual demonstra a importância da diversidade vegetal como forma de recurso na medicina popular das famílias locais. $\mathrm{O}$ quintal é, portanto, uma importante fonte medicinal local.

A diversidade de espécies existentes nos quintais é para Morán (1995) nada mais nada menos que a grande contribuição fornecida pelos imigrantes que, vindos de todas as regiões do Brasil, trouxeram em sua bagagem um pouco de seus hábitos culturais que foram disseminados ao longo do tempo nas mais diversas regiões do Brasil. Nesse caso, podemos citar alguns exemplos que tipificam a origem das pessoas da região, como o jenipapo trazido da Amazônia e a tanchagem introduzida pelos sulistas pelo processo de colonização da região.

Corroborando com os dados, Moura (2002) ressalta a comprovação da ação farmacológica dos extratos aquoso e hidroalcoólico do guaco e lista as indicações farmacológicas desta espécie: antiasmática, antigripal, antir- reumática, antisséptica das vias respiratórias, antitussígena, broncodilatadora, calmante e cicatrizante. Fierro et al. (1999) destacam, ainda, a ação anti-inflamatória de seu extrato etanólico.

Com base nessas avaliações farmacológicas, o guaco está incluído entre os fitoterápicos que fazem parte da Lista de Registro Simplificado de Fitoterápicos (LRSF) da Agência Nacional de Vigilância Sanitária (ANVISA).

Na comunidade local, a romã (Punica granatum L.) foi indicada para cinco tipos de doenças $(2,3 \%)$, demonstrando sua multiplicidade de uso, e $52 \%$ das plantas foram citadas para dois tipos de moléstias $(\mathrm{NU}=$ 2); $34 \%$ para três tipos de moléstias $(\mathrm{NU}=3)$; $7 \%$ para um tipo $(\mathrm{NU}=1)$; e $5 \%$ para quatro tipos $(\mathrm{NU}=4)$.

Entre os informantes locais, o alecrim (Rosmarinus officinalis L.) destacou-se em segundo lugar, apresentando frequência relativa de concordância quanto aos usos principais (PCUsp) de $84 \%$, sendo largamente utilizado para o tratamento de doenças cardiovasculares, como derrame, infarto do miocárdio, problemas de pressão, problemas de circulação sanguínea, formigamento nas extremidades das mãos e dos pés.

Corroborando os dados acima mencionados, Zeng et al. (2001) citam que o extrato do alecrim vem sendo usado na medicina popular na prevenção de doenças cardiovasculares, devido aos agentes antioxidantes 
diterpênicos do tipo fenólico, e do qual se pode extrair o carnosol, rosmanol e epirosmanol, usados no combate às doenças cardíacas e vasculares.

O não cumprimento de uma posologia formal quando da utilização dos remédios caseiros pode envolver consequências mais graves, pois algumas espécies vegetais possuem substâncias tóxicas em sua composição química, que, conforme a frequência de uso ou o tempo de utilização, podem causar problemas irreversíveis à saúde do ser humano.

Lagos-Witte (1998) constatou o grau de toxicidade aguda e subcrônica das preparações medicinais caseiras (decocto e macerado aquosos) realizadas com a entrecasca de Lafoensia pacari, onde a DL50 avaliada em ratos Wistar não foi alcançada na dose máxima de $5.000 \mathrm{mg} / \mathrm{kg}$, sugerindo que tanto o macerado, quanto o decocto não são capazes de causar danos ao usuário se soluções concentradas forem ingeridas em dose única. Quanto à toxicidade subcrônica dos extratos em diferentes concentrações, a autora afirma ter evidenciado algumas alterações bioquímicas decorrentes, provavelmente, de lesão hepática. Entretanto também declara ser necessário reproduzir o experimento para obter resultados conclusivos.

A medicina popular é inicialmente uma 'medicina de saber local', que designa certo modo de transmissão essencialmente oral e gestual (por ouvir falar e ver fazer), comunicada por intermédio da família e da vizinhança (PASA, 2011). Ela é praticada no cotidiano e se compõe de receitas cuja base é essencialmente vegetal e de conhecimentos e habilidades que se inscrevem no âmbito do empirismo médico, fato ilustrado pela fala de uma informante:

“(...) o guaco tem de ser usado na quantia certa, se usa mais dá vômito e diarreia e também na época das regras não pode usar, ele dá hemorragia que só (...)" (F. A. B., 62 anos. V. G, MT).

Existem 49 tipos de doenças consideradas 'simples' pela população local, compreendendo os diferentes sistemas do organismo humano, os mais comuns representando os problemas genitourinários em geral $(22 \%)$, respiratórios $(20 \%)$, digestivos em geral $(18 \%)$, circulatório $(17 \%)$, endócrino $(9 \%)$, nervoso
$(6 \%)$, tecido cutâneo (5\%) e esquelético-muscular $(3 \%)$; dados semelhantes foram apresentados por Pasa et al. (2005), Pasa (2007), Pasa e Ávila (2010), Pasa e Bastos (2010, Pasa e Oliveira (2013) e Guarim Neto (1996).

Das 86 espécies citadas, 35\% apresentaram frequência de concordância de usos principais (ICUsp) maior ou igual a 50\%, sugerindo a possibilidade de que essas espécies sejam comuns e presentes na região, sendo utilizadas regularmente pela população. Entre as espécies citadas, o guaco apresentou Nível de Fidelidade (NF) de 86,8\%, seguido do alecrim, com $84,4 \%$, entre outras com larga utilização pela comunidade local. Estudos etnobotânicos citaram a caapeba ou pariparoba (Pothomorphe umbellata (L.) M.) como uma espécie de erva medicinal usada por curandeiros no tratamento de picadas de cobras, especialmente envenenamentos. Outros usos mencionados foram problemas estomacais, digestivos e para emagrecimento (OSÓRIO; MARTINS, 2004).

Das 30 espécies que apresentaram concordância quanto aos usos principais (ICUsp) acima de $50 \%$, são referidos seis casos para problemas gástricos e circulatórios $(20 \%$ cada); cinco casos para problemas genitourinários (16,5\%); e o restante representa $43,5 \%$. Os dados obtidos são consoantes às categorias de doenças acima referidas em relação aos percentuais encontrados para o total das plantas usadas como medicinais na região.

A frequência relativa de concordância quanto aos usos principais (ICUsp) é demonstrada pelo nível de fidelidade entre os informantes, o que, necessariamente, não deve representar um ICUsp alto, podendo ser influenciada pelo tamanho da amostra (Fsp), de modo que, quanto menor a amostra, menor será o fator de correção (FC) e, consequentemente, menor o valor de ICUsp. Esses são os casos das plantas erva-de-santamaria (Chenopodium ambrosioides L.) e amescla (Protium heptaphyllum (Aubl.) March). Assim, o nível de fidelidade pode ser indicativo do saber local quanto ao uso das plantas na medicina popular.

As pessoas idosas, acima de 60 anos, representaram $14 \%$ do total de entrevistados, demonstraram conhecer os usos terapêuticos das plantas e maior multiplicidade de uso para as diferentes afecções mencionadas, 
fato que reflete forte consistência cultural de uso da medicina popular na comunidade. E informantes com idade entre 20 e 50 anos mostraram conhecer menos as plantas e ter menor conhecimento quanto à multiplicidade de uso delas, referindo-se a espécies comuns, como a goiaba (Psidium guajava L.) e o boldo (Coleus barbatus Benth.), para doenças consideradas 'simples', como diarréia e indigestão, respectivamente.

A inversão proporcional dos resultados, considerada sob o ponto de vista cultural, provavelmente pode ser explicada pela importância que existe na relação do ser humano com o ambiente em que vive e convive, expressa por meio das experiências pessoais, da convivência e das necessidades de sobrevivência.

Entre as plantas usadas na comunidade local, a frequência relativa de concordância quanto aos usos principais (PCUsp) ressaltou o guaco (Mikania glomerata Sprengel) com $87 \%$. Essa planta é largamente utilizada pela população local para tratamentos de problemas respiratórios, principalmente no inverno, que coincide com a estiagem e com a baixa umidade relativa do ar, chegando a valores entre $15 \%$ e $20 \%$, determinante de um clima seco, desencadeando, inevitavelmente, inúmeros problemas respiratórios e processos alérgicos das vias respiratórias (Tabela 2).

Tabela 2 - Valor relativo de concordância quanto aos usos principais. Várzea Grande, MT. 2013.

\begin{tabular}{|c|c|c|c|c|c|c|c|}
\hline NOME POPULAR & DOENÇA & Fsp & Fid & $\mathbf{N u}$ & NF & FC & Pcup(\%) \\
\hline Guaco & Doenças respiratórias & 38 & 33 & 3 & 86,8 & 1,00 & 87 \\
\hline Alecrim & Doenças cardiovasculares & 37 & 32 & 3 & 84,4 & 0,97 & 84 \\
\hline Erva de Santa Maria & Vermes & 31 & 31 & 2 & 100 & 0,81 & 81 \\
\hline Carqueja & Problemas de fígado & 35 & 30 & 3 & 85,7 & 0,92 & 79 \\
\hline Mangava brava, piúna & Gastrite & 32 & 29 & 3 & 90,5 & 0,84 & 76 \\
\hline Espinheira santa & Doenças do sangue & 37 & 28 & 2 & 75,5 & 0,97 & 73 \\
\hline Poejo & Resfriado & 34 & 28 & 3 & 82,3 & 0,89 & 73 \\
\hline Boldo & Problemas digestivos & 31 & 27 & 2 & 87,0 & 0,81 & 70 \\
\hline Guaraná & Fadiga & 31 & 27 & 2 & 87,0 & 0,81 & 70 \\
\hline Douradinha & Reumatismo & 34 & 26 & 3 & 76,4 & 0,89 & 68 \\
\hline Limão & Hipertensão arterial & 38 & 25 & 2 & 65,7 & 1,00 & 66 \\
\hline Quebra pedra & Cálculo renal & 31 & 24 & 2 & 77,4 & 0,81 & 64 \\
\hline Romã & Inflamação da garganta & 28 & 23 & 5 & 82,1 & 0,73 & 60 \\
\hline Mamão & Doenças gástricas & 30 & 22 & 2 & 73,3 & 0,78 & 57 \\
\hline Erva-de-bicho & Hemorroida & 25 & 22 & 2 & 88,0 & 0,65 & 57 \\
\hline Amescla & Doenças respiratórias & 22 & 22 & 1 & 100 & 0,57 & 57 \\
\hline Goiaba & Diarreia & 21 & 21 & 1 & 100 & 0,55 & 55 \\
\hline Confrei & Inflamação do útero & 34 & 20 & 2 & 58,8 & 0,89 & 52 \\
\hline Algodão do campo & Inflamação do útero e ovário & 29 & 20 & 3 & 69,0 & 0,76 & 52 \\
\hline Nó de cachorro & Fadiga & 29 & 19 & 4 & 65,5 & 0,76 & 50 \\
\hline Mangaba & Úlcera & 29 & 19 & 1 & 65,5 & 0,76 & 50 \\
\hline Copaíba, pau d'óleo & Inflamações em geral & 21 & 19 & 2 & 90,0 & 0,55 & 49 \\
\hline Malva branca, malva seda & Inflamação do útero e ovário & 29 & 18 & 2 & 62,0 & 0,76 & 47 \\
\hline Erva cidreira & Ansiedade & 25 & 18 & 3 & 72,0 & 0,65 & 47 \\
\hline Pata de vaca & Diabetes & 25 & 18 & 3 & 72,0 & 0,65 & 47 \\
\hline Tansagem & Inflamação do ovário & 32 & 18 & 4 & 56,2 & 0,84 & 47 \\
\hline Jurubeba & Problemas do fígado & 27 & 16 & 3 & 59,2 & 0,71 & 42 \\
\hline Algodão bálsamo & Inflamação do útero e ovário & 22 & 16 & 2 & 72,7 & 0,57 & 42 \\
\hline Cana de macaco & Infecção dos rins & 18 & 16 & 2 & 88,8 & 0,47 & 42 \\
\hline Maracujá & Ansiedade & 16 & 16 & 1 & 100 & 0,42 & 42 \\
\hline Gengibre & Doenças respiratórias & 16 & 16 & 3 & 100 & 0,42 & 42 \\
\hline Abóbora & Vermífugo & 15 & 15 & 1 & 100 & 0,39 & 39 \\
\hline Carambola & Diabetes & 19 & 14 & 2 & 73,6 & 0,50 & 37 \\
\hline Couve & Furunculose & 20 & 13 & 2 & 65,0 & 0,52 & 34 \\
\hline Velame branco & Doenças do sangue & 31 & 12 & 3 & 38,7 & 0,81 & 31 \\
\hline Três-marias & Amarelão & 21 & 12 & 3 & 57,1 & 0,55 & 31 \\
\hline Fedegoso & Problemas do fígado & 16 & 12 & 3 & 75,0 & 0,42 & 31 \\
\hline Sete sangrias & Pressão alta & 26 & 11 & 3 & 42,3 & 0,68 & 29 \\
\hline Acerola & Resfriado & 22 & 11 & 3 & 50,0 & 0,57 & 29 \\
\hline
\end{tabular}




\begin{tabular}{llcccccc}
\hline NOME POPULAR & DOENÇA & Fsp & Fid & Nu & NF & FC & Pcup(\%) \\
\hline Fruta pão & Diabete & 17 & 11 & 2 & 64,7 & 0,44 & 29 \\
Macela & Problemas digestivos & 15 & 11 & 1 & 73,3 & 0,39 & 28 \\
Algodãozinho & Inflamação do útero e ovário & 15 & 10 & 3 & 66,6 & 0,39 & 26 \\
Jambolão & Diabete & 15 & 10 & 2 & 66,6 & 0,39 & 26 \\
Camomila & Constipação intestinal & 18 & 9 & 2 & 50,0 & 0,47 & 24 \\
Hortelã do campo & Vermes & 11 & 9 & 2 & 81,8 & 0,28 & 23 \\
Pitanga & Diabete & 17 & 8 & 3 & 47,0 & 0,44 & 21 \\
Tomate & Diurético & 14 & 8 & 3 & 57,1 & 0,36 & 21 \\
Caferana & Problemas circulatórios & 13 & 8 & 2 & 61,5 & 0,34 & 21 \\
Chapéu de couro & Reumatismo & 12 & 8 & 2 & 66,6 & 0,31 & 21 \\
Manacá & Frieiras & 12 & 8 & 3 & 66,6 & 0,31 & 21 \\
Milho & Problemas urinários & 13 & 7 & 2 & 53,8 & 0,34 & 18 \\
Açafrão & Anemia & 11 & 7 & 2 & 63,6 & 0,28 & 18 \\
Coroa de frade & Doenças do sangue & 11 & 7 & 2 & 63,6 & 0,28 & 18 \\
\hline Abreviaçס̃
\end{tabular}

Abreviações: Fsp = Frequência absoluta dos informantes que citaram a espécie; Fid = Frequência absoluta dos informantes que citaram os usos principais; $\mathbf{N u}=$ Número de usos citados; $\mathbf{N F}=$ Nível de fidelidade; $\mathbf{F C}=$ Fator de Correção; Pcup = Frequência relativa de concordância quanto aos usos principais.

Os resultados permitiram visualizar a diversidade de uso terapêutico local. Os dados obtidos mostraram que 35\% (ICUsp igual ou maior que $50 \%$ ) do total das espécies são conhecidas e usadas pela maioria dos informantes através de sua multiplicidade de usos no tratamento das diversas doenças referidas. Essas espécies são altamente valorizadas pelas suas diversificações nas aplicações terapêuticas e não apresentam exploração comercial na região.

Considerando-se que o número de usos das plantas variou de 1 a 5, é possível que não exista relação entre alto manuseio, alta densidade, alta frequência ou expressiva área basal das espécies, o que poderia sugerir a probabilidade de comercialização. Existe sim, o uso, a densidade e a frequência de uso com características para a subsistência familiar. Em média, cada informante mencionou o uso de três plantas com finalidades medicinais. As pessoas idosas demonstraram conhecer melhor as plantas quanto à multiplicidade de usos na medicina popular conduzidos, certamente, pela expressividade cultural herdada e adquirida de suas origens étnicas.

Os resultados mostram que muitas espécies tiveram confirmação de suas indicações etnofarmacológicas na literatura. Quando se comparou os dados etnofarmacológicos com os farmacológicos, verificou-se que a maioria das espécies $(65,2 \%)$ não teve qualquer estudo que confirmasse a indicação popular. Várias espécies tiveram alguma atividade farma- cológica confirmada na literatura, pode-se citar: Baccharis trimera (carqueja), com atividade bacteriostática e bactericida, atividade antinflamatória e analgésica; Cochlospermum regium (algodão): atividade depurativa e efetiva no tratamento de gastrite e úlcera; Curatella americana (lixeira): atividade antihipertensiva e vasodilatadora; Heliotropium indicum (crista-de-galo): atividade antinflamatória; Matricaria chamomila (camomila): efeito sedativo; Mikania cf. glomerata (guaco): atividade broncodilatadora; Myracrodruon urundeuva (aroeira): atividade cicatrizante, antinflamatória e analgésica.

Os resultados obtidos demonstram que as informações relatadas pelas pessoas locais, quanto ao uso terapêutico das plantas citadas como medicinais, coincidem em quase $50 \%$ com as indicações etnofarmacológicas encontradas na literatura, no entanto em torno de $30 \%$ já possuem alguma atividade farmacológica comprovada.

As informações de saber local sobre o uso das plantas como remédio emitidas pelas pessoas da comunidade local oferecem subsídios para estudos científicos futuros. Estudos, especialmente os de natureza de fitoquímicos, farmacológicos e de controle de qualidade de plantas medicinais, são necessários para avaliação dos seus efeitos farmacológicos e toxicológicos e assim, buscando estratégias seguras para o uso dessas plantas e para a produção de fitoterápicos que possivelmente entrarão no mercado para comercialização. 


\section{Conclusões}

A conservação da biodiversidade é gerada através dos usos e dos conhecimentos tradicionais e de práticas conservacionistas tornando-se vantajosas pelos saberes etnobotânicos, etnoecológicos e etnobiológicos. Dessa forma, o conhecimento gerado através do resgate do saber popular e cultural da população varzea-grandense deve ser valorizado e divulgado, através de ações que viabilizem e garantam o uso dos recursos vegetais, especialmente com plantas de uso medicinal.

\section{Referências}

ADU-TUTU, M.; AFFUL, Y.; ASANTE-APPIAH, K.; LEBERMAN, D.; HALL, J. B.; ELVIN-LEWIS, M. Chewing stick usage in southern Ghana. Economic Botany, Bronx, v. 33, n. 3, p. 320-328, 1979.

AGRA, Maria de Fátima; SILVA, Kiriaki Nurit; BASÍLIO, Ionaldo José de Lima Diniz; FREITAS, Patrícia França; BARBOSA-FILHO, José Maria. Survey of medicinal plants used in the region Northeast of Brazil. Revista Brasileira de Farmacognosia, Curitiba, v. 18, n. 3, p. 472-508, 2008.

AKERELE, Olubanke. Summary of WHO guidelines for the assessment of herbal medicines. HerbalGram, Austin, v. 28, p. 13-19, 1993.

ALBUQUERQUE, Ulisses Paulino; ANDRADE, Laise de Holanda Cavalcanti. Uso de recursos vegetais da caatinga: o caso do agreste do estado de Pernambuco (Nordeste do Brasil). Interciência, Caracas, v. 27, n. 7, p. 336-346, 2002.

ALMEIDA, Edvaldo Rodrigues de. Plantas medicinais brasileiras: conhecimentos populares e científicos. São Paulo: Hemus, 1993.

AMOROZO, Maria Christina Mello; GÉLY, Anne. O uso de plantas medicinais por caboclos do baixo Amazonas, Barcarena, PA, Brasil. Boletim do Museu Paraense Emílio Goeldi, Série Botânica, Belém, v. 4, n. 1, p. 47-131, 1988.

BARRERA, A. La Etnobotânica. In: BARRERA, A. La Etnobotânica: três puntos de vista e uma perspectiva. Xalapa, México: Instituto de Investigacion sobre Recursos Bióticos, 1979. p. 19-25.

BORBA, Aneliza Meireles; MACEDO, Miramy. Plantas medicinais usadas para a saúde bucal pela comunidade do Bairro Santa Cruz, Chapada dos Guimarães, MT, Brasil. Acta Botanica Brasilica, Belo Horizonte, v. 20, n. 4, p. 771-782, 2006.

BRASIL. Ministério das Minas e Energia. Secretaria-Geral. Projeto RADAMBRASIL (Levantamento de Recursos Naturais, 21). Folha SD-21, Cuiabá. Rio de Janeiro, 1982. p. 1-540.
CABALLERO, Javier. La Etnobotânica. In: BARRER, A. (Ed.). La Etnobotânica: tres puntos de vista y uma perspectiva. Xalapa: Instituto de Investigación sobre Recursos Bióticos, 1979. p. 27-30.

DE LA CRUZ, Mari Gema Motta; GUARIM NETO, Germano. Plantas medicinais utilizadas por agentes de saúde em Cuiabá - MT. Um estudo etnobotânico. In: SIMPÓSIO DE PLANTAS MEDICINAIS DO BRASIL, 14., Florianópolis, 1996. Resumos... Florianópolis: UFSC, 1996.

ELIZABETSKY, Elaine. Etnofarmacologia de algumas tribos brasileiras. In: RIBEIRO, Berta (Org.). Suma etnológica brasileira. Petrópolis, RJ: Vozes, 1987. p. 68-75.

FARNSWORTH, Norman. An approach utilizing information from traditional medicine to identify tumor-inhibiting plants. Journal of Ethnopharmacology, v. 3, n. 1, p. 85-99, 1981.

FIERRO, I. M.; SILVA, A. C. B.; LOPES, C. S.; MOURA, R. S.; BARJAFIDALGO, C. Studies on the anti-allergic activity of Mikania glomerata. Journal of Ethnopharmacology, v. 66, n. 1, p. 19-24, 1999.

FRIEDMAN, John. A preliminary classification of the healing potential of medicinal plants, based on a rational analysis of ethnopharmacology field survey among bedouins in the Negev desert, Israel. Journal of Ethnopharmacology, v. 16, n. 2-3, p. 275-287, 1986.

FUNDAÇÃO NACIONAL DESAÚDE. MINISTÉRIO DA SAÚDE - FUNASA. Cemitérios como Fonte Potencial de Contaminação das Águas Subterrâneas Região de Cuiabá e Várzea Grande (MT). Relatório Final. Brasília, 2007. 117 p.

GUARIM NETO, Germano. Plantas utilizadas na medicina popular cuiabana - um estudo preliminar. Revista da Universidade Federal de Mato Grosso, Cuiabá, v. 4, n. 1, p. 45-50, 1984.

Plantas medicinais do Estado do Mato Grosso. Brasília: ABEAS/UFMT, 1996. 72p.

INSTITUTO NACIONAL DE METEOROLOGIA DO MINISTÉRIO DA AGRICULTURA - INMET. Boletim Agroclimatológico, Brasília, v. 30, n.1, p. 1-12, 1996.

LAGOS-WITTE, Sonia Raices. La investigación etnobotânica y su integración a programas de desarrollo en salud. Buenos Aires: CETAAR, 1998.

LEITÃO, Fernanda; FONSECA-KRUEL, Viviane Stern; SILVA, Inês Machline; REINERT, Fernanda. Urban ethnobotany in Petrópolis and Nova Friburgo (Rio de Janeiro, Brazil). Revista Brasileira de Farmacognosia, Curitiba, v. 19, n. 1, p. 333-342, jan./mar. 2009.

MACHADO, A.Q.; ROMIO, A. M.G.; CHITARRA, G. S. Seleção de cultivares de tomate para plantio em 
Várzea Grande-MT. Várzea Grande, MT: UNIVAG Centro Universitário; Grupo de Produção Acadêmica de Ciências Agrárias e Biológicas, [s.d.]. Disponível em <http://www.abhorticultura. com.br/biblioteca/arquivos/Download/Biblioteca/46_0256.pdf>. Acesso em: 3 maio 2013.

MARLIÉRE, Luciano; RIBEIRO, Andréia; BRANDÃO, Maria das Graças; KLEIN, Carlos Henrique; ACURCIO, Francisco de Assis. Utilização de fitoterápicos por idosos: resultados de um inquérito domiciliar em Belo Horizonte (MG), Brasil. Revista Brasileira de Farmacognosia, Curitiba, v. 18 (suplemento), p. 754-760, dez. 2008.

MINAYO, Maria Cecília de Souza. O desafio do conhecimento: pesquisa qualitativa em saúde. São Paulo: HUCITEC; Rio de Janeiro: ABRASCO, 1992.

MORÁN, E. F. Introduction: norms for ethnographic reporting. In: MORAM, E. F. (Ed.). The comparative analysis of human societies. Toward common standarts for data collection and reporting. Boulder: Lynne Rienner Publishers, 1995.

MOURA, Roberto Soares de. Bronchodilator activity of Mikania glomerata Sprengel on human bronchi and guinea-pig trachea. Journal of Pharmacy and Pharmacology, v. 54, n. 2, p. 249-256, 2002.

NAIR, P. K. R. An Introduction to Agroforestry. Dordrecht, The Netherlands: ICRAF/Kluwer Academic Publishers. 401p.1993.

OLIVEIRA, A. G. Avaliação das temperaturas superficiais do solo em relação à conformação urbana existente na Praça do Aeroporto Marechal Rondon em Várzea Grande/MT. 2008. 81f. Dissertação (Mestrado em Física e Meio Ambiente) - Instituto de Ciências Exatas e da Terra, Universidade Federal de Mato Grosso, Cuiabá, MT, 2008.

OSÓRIO, Adriana de Carvalho; MARTINS, Jorge Luiz Seferin. Determinação de cumarina em extrato fluido e tintura de guaco por espectrofotometria derivada de primeira ordem. Revista Brasileira de Ciências Farmacêuticas, São Paulo, v. 40, n. 4, p. 481-486, 2004.

PASA, Maria Corette; SOARES, João Juares; GUARIM NETO, Germano. Estudo etnobotânico na comunidade de Conceição-Açu (alto da bacia do rio Aricá Açu, MT, Brasil). Acta Botanica Brasilica, Belo Horizonte, v. 19, n. 2, p. 195-207, 2005.

PASA, Maria C.; ÁVILA, Gabriela. Ribeirinhos e recursos vegetais: a etnobotânica em Rondonópolis,
Mato Grosso, Brasil. Interações, Campo Grande, MS, v. 11, n. 2, p. 195-204, jul./dez. 2010.

PASA, Maria Corette; BASTOS, Eliana Alves Santos. A etnobiologia no fragmento florestal Recanto do Sol, Campo Verde, Mato Grosso. In: SANTOS, J. W. M. C. (Ed.). Produção do espaço e transformações socioambientais das paisagens do Mato Grosso. Cuiabá: EDUFMT, 2010. p. 60-82.

PASA, Maria Corette; OLIVEIRA, Waleska Arruda. In: PASA Maria Corette (Org.). Múltiplos olhares sobre a biodiversiade: os quintais na Comunidade de Santo Antônio do Caramujo: etnobotânica e saber local. São Paulo: Pacoeditorial, 2013. p. 47-74.

PASA, Maria Corette. Um olhar etnobotânico sobre as comunidades do Bambá, Cuiabá, MT. Cuiabá: Entrelinhas, 2007. 168p.

Abordagem etnobotânica na Comunidade de Conceição-Açú, Mato Grosso, Brasil. Polibotânica, México, v. 31, p. 169-197, 2011.

PHILLIPS, Oliver. Some quantitative methods for analyzing ethnobotanical knowledge. In: ALEXIADES, M. (Ed.). Selected Guidelines for Ethnobotanical Research: a field manual. New York: Missouri Botanical Garden, 1996. p. 172-197.

SANTOS, Esther Bandeira; DANTAS, Gerisa Soares; SANTOS, Hosana Bandeira; DINIZ, Margarete Melo; SAMPAIO, Fabio Correia. Estudo etnobotânico de plantas medicinais para problemas bucais no município de João Pessoa, Brasil. Revista Brasileira de Farmacognosia, Curitiba, v. 19, n. 1, p. 321-324, jan./mar. 2009.

VEIGA JUNIOR, Valdir Florêncio. Estudo do consumo de plantas medicinais na Região CentroNorte do Estado do Rio de Janeiro: aceitação pelos profissionais de saúde e modo de uso pela população. Revista Brasileira de Farmacognosia, Curitiba, v. 18, n. 2, p. 308-313, abr./jun. 2008.

VENDRUSCOLO, Giovana Secretti; MENTZ, Lilian Auler. Estudo da concordância das citações de uso e importância das espécies e famílias utilizadas como medicinais pela comunidade do bairro Ponta Grossa, Porto Alegre, RS, Brasil. Acta Botanica Brasilica, Belo Horizonte, v. 20, n. 2, p. 367-382, 2006.

ZENG, H.; TU, P. F.; ZHOU, K.; WANG, H.; WANG, B. H.; LU, J. F. Antioxidant properties of phenolic diterpenes fom Rosmarinus officinalis. Acta Pharmacologica Sinica, Shanghai, v. 22, n. 12, p. 1094-1098, 2001. 